\title{
Altered long non-coding RNAs predict worse outcome in osteosarcoma patients: evidence from a meta-analysis
}

\author{
Yanliang Yang ${ }^{1}$, Shunli Wang ${ }^{1}$ and Teng Li ${ }^{1}$ \\ ${ }^{1}$ Bone Tumour \& Bone Disease Department I, Zhengzhou Orthopaedics Hospital, Zhengzhou Orthopedics Hospital Affiliated \\ to Henan University, Henan, China \\ Correspondence to: Yanliang Yang, email: ylyang2006@163.com
}

Keywords: osteosarcoma, IncRNA, prognosis, meta-analysis

Received: November 01, $2016 \quad$ Accepted: March 10, 2017

Published: March 22, 2017

Copyright: Yang et al. This is an open-access article distributed under the terms of the Creative Commons Attribution License (CC-BY), which permits unrestricted use, distribution, and reproduction in any medium, provided the original author and source are credited.

\section{ABSTRACT}

Long non-coding RNAs (IncRNAs) are emerging as promising prognostic biomarkers in an expanding list of malignant neoplasms. Here, we sought to investigate the strength of associations between IncRNA signatures and clinical outcomes in osteosarcoma. We conducted a systematic search of the online databases from inception to July 2016. Hazard ratios (HRs) with corresponding $95 \%$ confidence intervals (CIs) for the primary endpoints of overall survival (OS), progression-free survival (PFS) or event-free survival (EFS) were extracted and meta-analyzed. Our results manifested that altered IncRNAs expression was markedly associated with worse OS (univariate analysis: $H R=3.20,95 \%$ CI: 2.42-4.24, $P=0.000$; multivariate analysis: $H R=2.66,95 \%$ CI: $1.92-3.69, P=0.000)$, PFS $(H R=2.05,95 \%$ CI: $1.32-$ $3.18, P=0.001)$ and EFS (HR $=4.37,95 \% C I: 1.64-11.66, P=0.003)$ times among osteosarcoma patients. In the pooled analyses stratified by clinicopathological features, levels of IncRNAs were closely correlated with tumor size (pooled $P=$ 0.001 ), tumor stage (pooled $P=\mathbf{0 . 0 0 3}$ ), and distant metastasis (pooled $P=\mathbf{0 . 0 0 2}$ ) in osteosarcoma. The results obtained in our work suggest that altered IncRNA signatures predict unfavorable clinical outcomes and are acceptable to be potential prognostic biomarkers in forecasting prognosis of osteosarcoma.

\section{INTRODUCTION}

Osteosarcoma represents $55 \%$ of all specified malignant bone cancers in adolescences under the age of twenty [1]. More than 20\% of the young-onset osteosarcoma patients present with distant metastases at diagnosis, and $40 \%$ cases in advanced stages progress to metastasis during therapy [2]. Despite the developments of novel treatment strategies, patients suffered from osteosarcoma still evolve with a dissatisfying prognosis. It is reported that the 5-year survival rate of osteosarcoma is lower than $62 \%$ in patients with localized disease, yet in those with recurrent or metastatic status, this rate will be attenuated to about $20 \%$ [1,3]. In consequence, there is a critical need to find and develop novel prognostic biomarkers in monitoring progression and survival of osteosarcoma in clinic.

Recently, the discovery of the long non-coding RNAs (lncRNAs) has provided new insights into cancer research. LncRNA is defined as one kind of endogenous
RNA comprises a sequence larger than 200 nucleotides but with no significant or functional open reading frame(s) [4]. Since their discoveries, lncRNAs are being investigated at a rapid pace and the corresponding functions are being interpreted. At present, lncRNAs have been confirmed to be implicated in regulation of diverse biological processes, including gene expression, cell proliferation, apoptosis, migration, and protein localization, etc [5-7]. More than that, many investigations have indicated promising results for the potential value of lncRNAs as prognostic indicators in cancers [8-11]. For instance, a meta-analysis from Chen et al reported that altered lncRNAs were not only associated with poor prognoses in renal cell carcinoma cancer, but also correlated to lymph node metastasis and distant metastasis of the disease, thereby recommending their potential clinical applications as novel biomarkers in forecasting prognosis or guiding therapeutics [11].

Till now, the prognostic roles of multi-types of lncRNAs have been investigated in osteosarcoma as well, consisting of HULC, HOTTIP, MEG3, TUSC7, 
TUG1, 91H, and OMRUL, etc [12-23]. All of the abovementioned lncRNA signatures have in common that testing of lncRNA(s) levels may be served as potential and efficient prognostic markers for osteosarcoma. Nevertheless, no meta-analysis has been conducted to provide a comprehensive overview of the clinical utilities of lncRNAs in surveillance of osteosarcoma prognosis. Herein, we established standardized inclusion criteria and statistical approach, and conducted this meta-analysis with the purpose of giving a comprehensive evaluation of the associations between lncRNA signatures and clinical outcomes in osteosarcoma.

\section{RESULTS}

\section{Study selection and characteristics}

The procedure of literature inclusion and exclusion is illustrated in Figure 1. According to the predefined criteria, a total of 84 records were obtained from the online PubMed, EMBASE, Chinese National Knowledge Infrastructure (CNKI), and WANFANG databases after duplicates removed. After the manual screening, 61

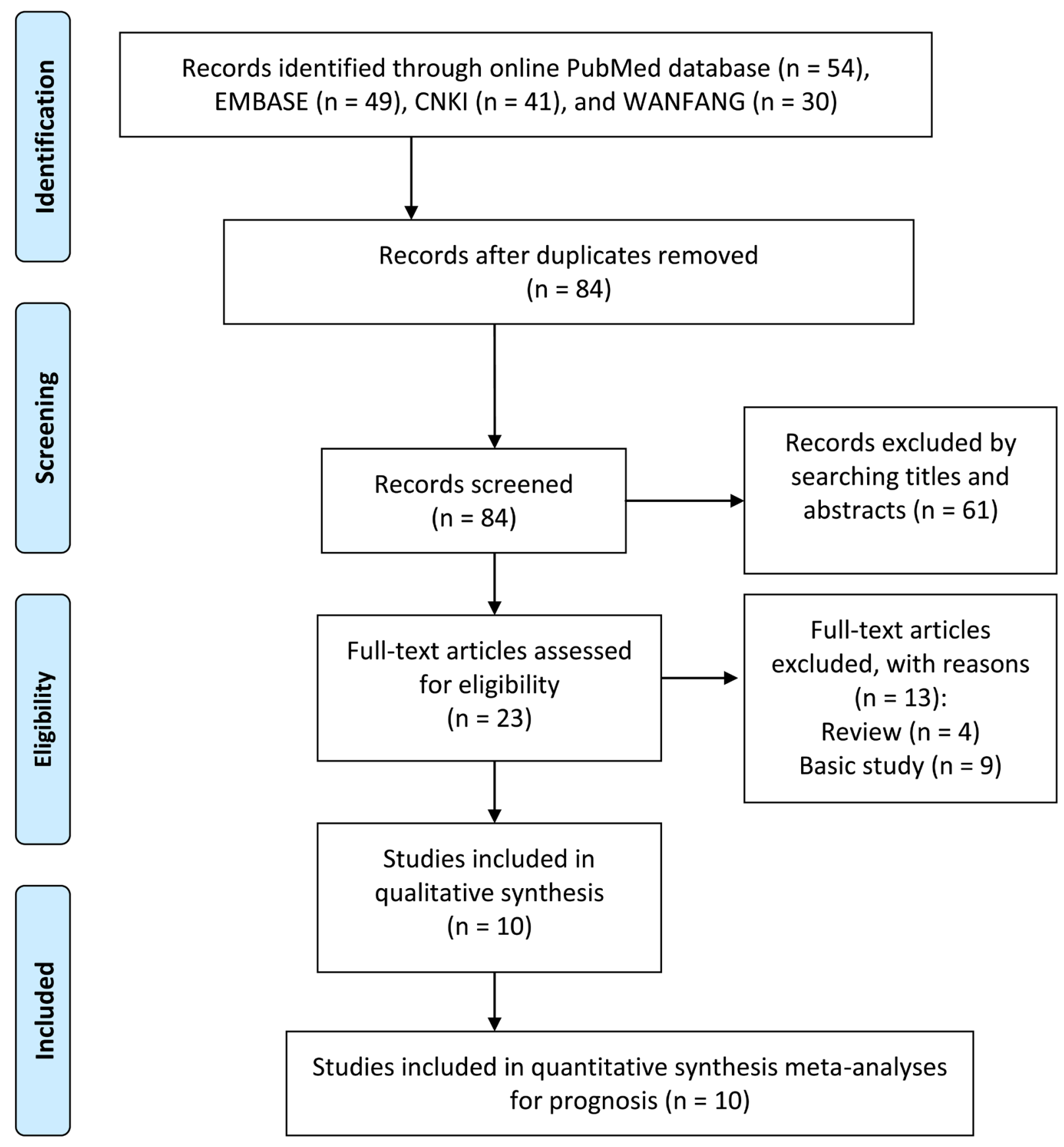

Figure 1: Flow diagram of study selection procedure. 
Table 1: Summary of IncRNAs used as prognostic biomarkers in forecasting osteosarcoma

\begin{tabular}{|c|c|c|c|c|c|c|c|c|c|c|c|c|c|c|}
\hline \multirow{2}{*}{ Author } & \multirow{2}{*}{ Year } & \multirow{2}{*}{ Area } & \multirow{2}{*}{$\begin{array}{l}\text { Study } \\
\text { design }\end{array}$} & \multirow{2}{*}{$\begin{array}{c}\text { Patient } \\
\text { size }\end{array}$} & \multirow{2}{*}{$\begin{array}{c}\text { Tumor stage } \\
\text { I+II (\%) }\end{array}$} & \multicolumn{2}{|c|}{ LncRNAs } & \multirow{2}{*}{$\begin{array}{c}\text { Sample } \\
\text { type }\end{array}$} & \multirow{2}{*}{$\begin{array}{c}\text { Test } \\
\text { method }\end{array}$} & \multirow{2}{*}{$\begin{array}{c}\text { Reference } \\
\text { gene }\end{array}$} & \multirow{2}{*}{$\begin{array}{l}\text { Survival } \\
\text { indicator }\end{array}$} & \multirow{2}{*}{$\begin{array}{l}\text { HR\&95\%CI } \\
\text { availability }\end{array}$} & \multirow{2}{*}{$\begin{array}{c}\text { Follow-up } \\
\text { months }\end{array}$} & \multirow{2}{*}{$\begin{array}{l}\text { NOS } \\
\text { score }\end{array}$} \\
\hline & & & & & & Signature & Expression & & & & & & & \\
\hline Cong et al [13] & 2016 & China & $\mathrm{R}$ & 82 & 39.0 & TUSC7 & Decreased & Tissue & qRT-PCR & $\beta$-actin & OS & Directly & Unclear & 7 \\
\hline Li et al [14] & 2015 & China & $\mathrm{R}$ & 68 & 44.1 & HOTTIP & Increased & Tissue & qRT-PCR & GAPDH & OS & Directly & 60 & 7 \\
\hline Ma et al. [16] & 2016 & China & $\mathrm{R}$ & 76 & 84.2 & TUG1 & Increased & Tissue & qRT-PCR & $\beta$-actin & OS, PFS & Directly & Median: 44,24 & 8 \\
\hline Peng et al [17] & 2016 & China & $\mathrm{R}$ & 84 & 68.4 & BANCR & Increased & Tissue & qRT-PCR & GAPDH & os & Indirectly & Unclear & 7 \\
\hline Sun et al [18] & 2016 & China & $\mathrm{R}$ & 62 & 65.6 & FGFR3-AS1 & Increased & Tissue & qRT-PCR & $18 \mathrm{~S}$ rRNA & OS & Indirectly & Median: 31 & 8 \\
\hline Sun et al [19] & 2015 & China & $\mathrm{R}$ & 78 & 44.9 & HULC & Increased & Tissue & qRT-PCR & GAPDH & os & Directly & Unclear & 7 \\
\hline Tian et al [20] & 2015 & China & $\mathrm{R}$ & 64 & 48.4 & MEG3 & Decreased & Tissue & qRT-PCR & GAPDH & OS & Directly & $10-60$ & 7 \\
\hline Uzan et al [21] & 2016 & Brazil & $\mathrm{R}$ & 33 & 70.0 & HULC & Increased & Tissue & qRT-PCR & $\begin{array}{l}\text { GAPDH } \\
\text { \& actin }\end{array}$ & OS, EFS & Indirectly & 96 & 8 \\
\hline Xia et al [22] & 2016 & China & $R$ & 67 & 83.6 & $91 \mathrm{H}$ & Increased & Plasma & qRT-PCR & G3PDH & os & Directly & $60(3-60)$ & 8 \\
\hline Zhu et al [23] & 2015 & China & $\mathrm{R}$ & 60 & Unclear & OMRUL & Increased & Tissue & Microarray & GAPDH & os & Indirectly & $25(6-96)$ & 7 \\
\hline
\end{tabular}

R: retrospective study;OS: overall survival; PFS: progression-free survival; EFS: event-free survival.

Table 2: Associations observed between clinicopathological variables and OS time in osteosarcoma

\begin{tabular}{|c|c|c|c|c|c|c|c|c|}
\hline \multirow{3}{*}{ Factors } & \multicolumn{4}{|c|}{ Univariate analysis } & \multicolumn{4}{|c|}{ Multivariate analysis } \\
\hline & \multirow{2}{*}{$\begin{array}{l}\text { Pooled HR } \\
(95 \% \mathrm{CI})\end{array}$} & \multirow[t]{2}{*}{$P$ value } & \multicolumn{2}{|c|}{ Heterogeneity } & \multirow{2}{*}{$\begin{array}{c}\text { Pooled HR } \\
(95 \% \mathrm{CI})\end{array}$} & \multirow[t]{2}{*}{$P$ value } & \multicolumn{2}{|c|}{ Heterogeneity } \\
\hline & & & I-squared (\%) & Chi-squared $(P)$ & & & I-squared (\%) & Chi-squared $(P)$ \\
\hline \multicolumn{9}{|l|}{ Clinicopathological features } \\
\hline Age & $1.11(0.86-1.45)$ & 0.420 & 0.0 & 0.773 & & & & \\
\hline Gender & $1.06(0.83-1.37)$ & 0.623 & 0.0 & 0.879 & & & & \\
\hline Anatomic location & $1.00(0.76-1.32)$ & 0.996 & 0.0 & 0.783 & & & & \\
\hline Tumor size & $2.03(1.43-2.88)$ & 0.000 & 0.0 & 0.773 & & & & \\
\hline Tumor stage & $2.86(2.17-3.77)$ & 0.000 & 0.0 & 0.740 & $2.69(2.01-3.59)$ & 0.000 & 19.1 & 0.284 \\
\hline Distant metastasis & $3.64(2.70-4.91)$ & 0.000 & 0.0 & 0.571 & $3.35(2.48-4.51)$ & 0.000 & 0.0 & 0.780 \\
\hline Chemotherapy & $1.02(0.18-5.60)^{*}$ & $0.987^{*}$ & 90.1 & 0.001 & $1.28(0.72-2.27)$ & 0.396 & 54.0 & 0.140 \\
\hline \multicolumn{9}{|l|}{ Expression status } \\
\hline Up-regulated lncRNAs & $3.24(2.38-4.40)$ & 0.000 & 0.0 & 0.813 & $2.17(1.90-3.87)$ & 0.000 & 0.0 & 0.979 \\
\hline Down-regulated lncRNAs & $1.52(0.35-6.61)^{*}$ & $0.579 *$ & 83.2 & 0.003 & & & & \\
\hline
\end{tabular}

HR: hazard ratios; CI: confidence intervals. *indicates that data were obtained by using a random-effect model in the metaanalysis.

citations were excluded by searching titles and abstracts. Twenty three articles received full-text evaluation, and 13 publications were discarded either because the status of reviews or basic research articles. Finally, a total of 10 cohorts were evaluated for the final meta-analysis.

The major characteristics of each enrolled study are summarized in Table 1. Ten publications with a combined study population of 674 cases were included. All samples were retrieved prior to treatment and the final diagnosis all relied on the histopathological examinations. Expression status of all lncRNAs was determined by quantitative reverse transcription polymerase chain reaction (qRTPCR). The reference genes comprised DAPGH $[14,17$, 19-21, 23], G3PDH [22], $\beta$-actin [13, 16, 21], and 18S
rRNA [18]. The primary endpoints included OS, PFS, and EFS, with a median follow-up time ranged from 25 to 60 months. The altered lncRNA expression profile possessed a total of 9 individuals, yet 7 of them (TUG1, 91H, HULC, BANCR, FGFR3-AS1, HOTTIP, and OMRUL) were overexpressed in osteosarcoma tissues/plasma, and 2 (MEG3 and TUSC7) were down-regulated.

\section{Article quality and heterogeneity}

Article quality was judged by the NOS checklist [24], and total evaluation scores of each study regarding cohort selection, comparability and outcome ascertainment 
are summarized in Table 1. All studies retained NOS scores larger or equal to 7 , suggesting a relatively high quality of the included investigations.

For the heterogeneity analysis checked by I-squared and Chi-squared tests, we only observed a slight degree of heterogeneity in the analysis of pooled EFS (I-squared $=57.8 \%$ ), whereas other combined analyses involveded pooled of OS and PFS times, all showed no significant heterogeneity existed among studies. Additionally, heterogeneity appeared in the stratified analyses as Chemotherapy-based (I-squared $=90.1 \%, P=0.001$ in Chi-squared test) and down-regulated lncRNAs (I-squared $=83.2 \%, P=0.003$ in Chi-squared test) analyses (Table 2), and therefore the DerSimonian and Laird method was employed for statistical analysis.

\section{Results of the prognostic meta-analysis}

Our results manifested that altered lncRNA profiles were significantly associated with poor OS (univariate analysis: $\mathrm{HR}=3.20,95 \% \mathrm{CI}: 2.42-4.24, P=0.000$; multivariate analysis: $\mathrm{HR}=2.66,95 \% \mathrm{CI}: 1.92-3.69, P=$ $0.000)$, and also influenced both PFS ( $\mathrm{HR}=2.05,95 \% \mathrm{CI}$ $1.32-3.18, P=0.001)$ and $\mathrm{EFS}(\mathrm{HR}=4.37,95 \% \mathrm{CI}: 1.64-$ $11.66, P=0.003)$ among osteosarcoma patients (Figure 2).

\section{Subgroup analysis}

In the subgroup analysis stratified by clinicopathological features, significant negative

\begin{tabular}{|c|c|c|c|}
\hline $\begin{array}{l}\text { Study } \\
\text { ID }\end{array}$ & & $\mathrm{HR}(95 \% \mathrm{Cl})$ & $\begin{array}{l}\% \\
\text { Weight }\end{array}$ \\
\hline $\begin{array}{l}\text { OS (Univariate analysis) } \\
\text { Uzan }(2016) \\
\text { Cong }(2016) \\
\text { Sun }(2016) \\
\text { Zhu }(2015) \\
\text { Sun }(2015) \\
\text { Xia (2016) } \\
\text { Peng (2016) } \\
\text { Tian (2015) } \\
\text { Li (2015) } \\
\text { Ma (2016) } \\
\text { Subtotal (I-squared }=0.0 \%, p=0.913)\end{array}$ & & $\begin{array}{l}8.72(1.50,50.79) \\
3.99(1.15,13.91) \\
2.61(1.09,6.24) \\
4.50(1.73,11.68) \\
2.59(1.61,6.06) \\
3.13(1.31,7.46) \\
5.74(2.03,16.24) \\
2.73(1.57,7.72) \\
3.02(1.49,7.24) \\
2.77(1.29,5.98) \\
3.20(2.42,4.24)\end{array}$ & $\begin{array}{l}1.14 \\
2.26 \\
4.63 \\
3.86 \\
8.05 \\
4.66 \\
3.26 \\
5.57 \\
5.62 \\
5.99 \\
45.04\end{array}$ \\
\hline $\begin{array}{l}\text { OS (Multivariate analysis) } \\
\text { Xia (2016) } \\
\text { Peng (2016) } \\
\text { Tian }(2015) \\
\text { Li }(2015) \\
\text { Sun }(2015) \\
\text { Ma }(2016) \\
\text { Subtotal (l-squared }=0.0 \%, p=0.992)\end{array}$ & $\underset{+\infty}{\stackrel{\infty}{\longrightarrow}}$ & $\begin{array}{l}3.14(1.32,7.49) \\
2.93(1.12,7.66) \\
2.41(1.32,6.81) \\
2.89(1.37,7.06) \\
2.28(1.48,5.43) \\
2.78(1.29,6.00) \\
2.66(1.92,3.69)\end{array}$ & $\begin{array}{l}4.68 \\
3.81 \\
5.23 \\
5.23 \\
8.36 \\
5.96 \\
33.26\end{array}$ \\
\hline $\begin{array}{l}\text { PFS } \\
\mathrm{Ma}(2016) \\
\mathrm{Ma}(2016) \\
\text { Subtotal }(\text { l-squared }=0.0 \%, \mathrm{p}=0.589)\end{array}$ & $\infty$ & $\begin{array}{l}2.31(1.24,4.31) \\
1.81(1.01,3.54) \\
2.05(1.32,3.18)\end{array}$ & $\begin{array}{l}9.08 \\
8.96 \\
18.04\end{array}$ \\
\hline $\begin{array}{l}\text { EFS } \\
\text { Uzan }(2016) \\
\text { Uzan }(2016) \\
\text { Subtotal }(\text { l-squared }=57.8 \%, p=0.124)\end{array}$ & $\underset{\leftarrow}{\stackrel{1}{+\infty}}$ & \multicolumn{2}{|c|}{$\begin{array}{lr}22.01(2.26,216.13) 0.68 \\
3.03(1.01,8.87) & 2.99 \\
4.37(1.64,11.66) & 3.66\end{array}$} \\
\hline Heterogeneity between groups: $p=0.295$ & $\begin{array}{l}1 \\
1 \\
1 \\
1\end{array}$ & & \\
\hline .00463 & & & \\
\hline
\end{tabular}

Figure 2: Prognostic utilities of IncRNA signatures in predicting OS, PFS and EFS times in osteosarcoma. 
Table 3: Comparison of the $P$ values of correlations between IncRNA signature and clinicopathological features in osteosarcoma.

\begin{tabular}{|c|c|c|c|c|c|c|c|c|c|c|c|}
\hline \multirow[t]{2}{*}{ Study } & \multirow[t]{2}{*}{ Area } & \multicolumn{2}{|c|}{ LncRNAs } & \multirow{2}{*}{$\begin{array}{c}\text { Patient } \\
\text { size }\end{array}$} & \multirow[t]{2}{*}{ Gender } & \multirow[t]{2}{*}{ Age } & \multirow{2}{*}{$\begin{array}{c}\text { Tumor size } \\
\text { (cm) }\end{array}$} & \multirow{2}{*}{$\begin{array}{l}\text { Tumor } \\
\text { stage }\end{array}$} & \multirow{2}{*}{$\begin{array}{l}\text { Anatomic } \\
\text { location }\end{array}$} & \multirow{2}{*}{$\begin{array}{c}\text { Distant } \\
\text { metastasis }\end{array}$} & \multirow{2}{*}{$\begin{array}{c}\text { Chemotherapy } \\
\text { (Yes or No) }\end{array}$} \\
\hline & & Signature & os & & & & & & & & \\
\hline Cong 2016 [13] & China & TUSC7 & 0.030 & 82 & 0.650 & 0.473 & $\mathrm{NM}$ & 0.294 & 0.627 & 0.087 & NM \\
\hline Li 2015 [14] & China & HOTTIP & 0.007 & 68 & 0.465 & 0.215 & 0.120 & 0.003 & 0.161 & 0.016 & NM \\
\hline Ma 2016 [16] & China & TUG1 & 0.009 & 76 & 0.885 & 0.318 & 0.044 & 0.082 & 0.769 & 0.015 & 0.012 \\
\hline Peng 2016 [17] & China & BANCR & 0.028 & 84 & 0.509 & 0.505 & 0.008 & 0.004 & 0.814 & 0.02 & $\mathrm{NM}$ \\
\hline Sun 2016 [18] & China & FGFR3-AS1 & 0.031 & 62 & 0.611 & 0.309 & 0.041 & 0.013 & 0.490 & 0.030 & NM \\
\hline Sun 2015 [19] & China & HULC & 0.009 & 78 & 0.492 & 0.352 & 0.496 & 0.003 & 0.624 & 0.005 & $\mathrm{NM}$ \\
\hline Tian 2015 [20] & China & MEG3 & 0.006 & 64 & 0.614 & 0.302 & 0.076 & 0.006 & 0.281 & 0.011 & NM \\
\hline Uzan 2016 [21] & Brazil & HULC & 0.016 & 33 & 0.999 & 0.065 & 0.670 & 0.999 & 0.274 & 0.999 & $\mathrm{NM}$ \\
\hline Xia 2016 [22] & China & $91 \mathrm{H}$ & 0.01 & 67 & 0.806 & 0.738 & 0.073 & 0.106 & 0.653 & 0.007 & 0.030 \\
\hline Zhu 2015 [23] & China & OMRUL & 0.002 & 60 & NA & 0.100 & $\mathrm{NM}$ & NM & 0.070 & NM & NM \\
\hline
\end{tabular}

NM: not mentioned

associations were observed between OS time and the following variables: tumor size (univariate analysis: HR $=2.03,95 \% \mathrm{CI}: 1.43-2.88, P=0.000)$, clinical stage (univariate analysis: $\mathrm{HR}=2.86,95 \% \mathrm{CI}: 2.17-3.77$, $P=0.000$; multivariate analysis: $\mathrm{HR}=2.69,95 \% \mathrm{CI}$ : 2.01-3.59, $P=0.000$ ), and distant metastasis (univariate analysis: $\mathrm{HR}=3.64,95 \% \mathrm{CI}: 2.70-4.91, P=0.000$; multivariate: $\mathrm{HR}=3.35,95 \% \mathrm{CI}: 2.48-4.51, P=0.000$ ) (Supplementary Figure 1 to 3 and Table 2). Moreover, for the analyses based on expression status, the up-regulated lncRNAs were more likely to manifest shorter OS time (univariate analysis: $\mathrm{HR}=3.24,95 \% \mathrm{CI}: 2.38-4.40, P=$ 0.000 ; multivariate analysis: $\mathrm{HR}=2.17,95 \% \mathrm{CI}: 1.90$ 3.87, $P=0.000$ ) compared with the down-regulated lncRNAs in osteosarcoma (Supplementary Figure 1 to 3 and Table 2). Differences across other clinicopathological variables, including age, gender, anatomic location, chemotherapy and decreased lncRNA expression were not significant.

Comparison of the $P$ values of correlations between lncRNA signatures and clinicopathological features are documented in Table 3 and Supplementary Table 1. The data showed that lncRNAs expression was significantly correlated with tumor size (Chi-squared $=39.12$, pooled $P=0.001)$, tumor stage (Chi-squared $=65.14$, pooled $P=0.003$ ), and distant metastasis (Chi-squared = 65.93 , pooled $P=0.002$ ) in osteosarcoma, but was not significantly linked to gender, age, and anatomic location (Supplementary Table 1)

\section{Influence analysis and publication bias}

Sensitivity analysis were undertaken to deeply trace the outliers among studies. As indicated in Figure 3, no individual studies were assessed as outliers, hinting that the pooled results of our meta-analyzed data were reliable.

Degrees of publication bias were judged by Bgger's funnel plot and Egger's publication bias plot. As exemplified in Figure 4, both the two tests presented $P$ values larger than 0.5 in the overall pooled analyses, suggesting a low likelihood of significant bias due to article publication.

\section{DISCUSSION}

Osteosarcoma is a complex and aggressive primary bone sarcoma, making up 55\% of the specified bone cancers in adolescents with 0 to 19 years of age [1]. Despite the rapid advantages in diagnosis and therapeutics, the prognostic outcomes of osteosarcoma remain dissatisfying $[1,3]$. It is urgent to identify and develop novel markers or targets to aid in diagnosis, treatment, as well as prognosis of osteosarcoma. In recent years, lncRNAs have been highlighted as potential prognostic biomarkers for osteosarcoma [12-23]. In this respect, a comprehensive meta-analysis is warranted to present an overview of the prognostic utilities of lncRNAs for osteosarcoma. We therefore conducted this meta-analysis, attempting to assess the associations between lncRNA signatures and survival times in osteosarcoma.

Our results demonstrated that altered IncRNA signatures were significantly associated with shorter OS, PFS as well as EFS times in osteosarcoma. The pooled HR of OS time for univariate analysis was estimated to be $3.20(P=0.000)$, and that for multivariate analysis was $2.66(P=0.000)$, hinting that altered lncRNA expression, at least the current well-characterized lncRNAs, are acceptable to be novel indicators in forecasting prognosis 
A

Meta-analysis estimates, given named study is omitted

| Lower Cl Limit O Estimate

| Upper Cl Limit

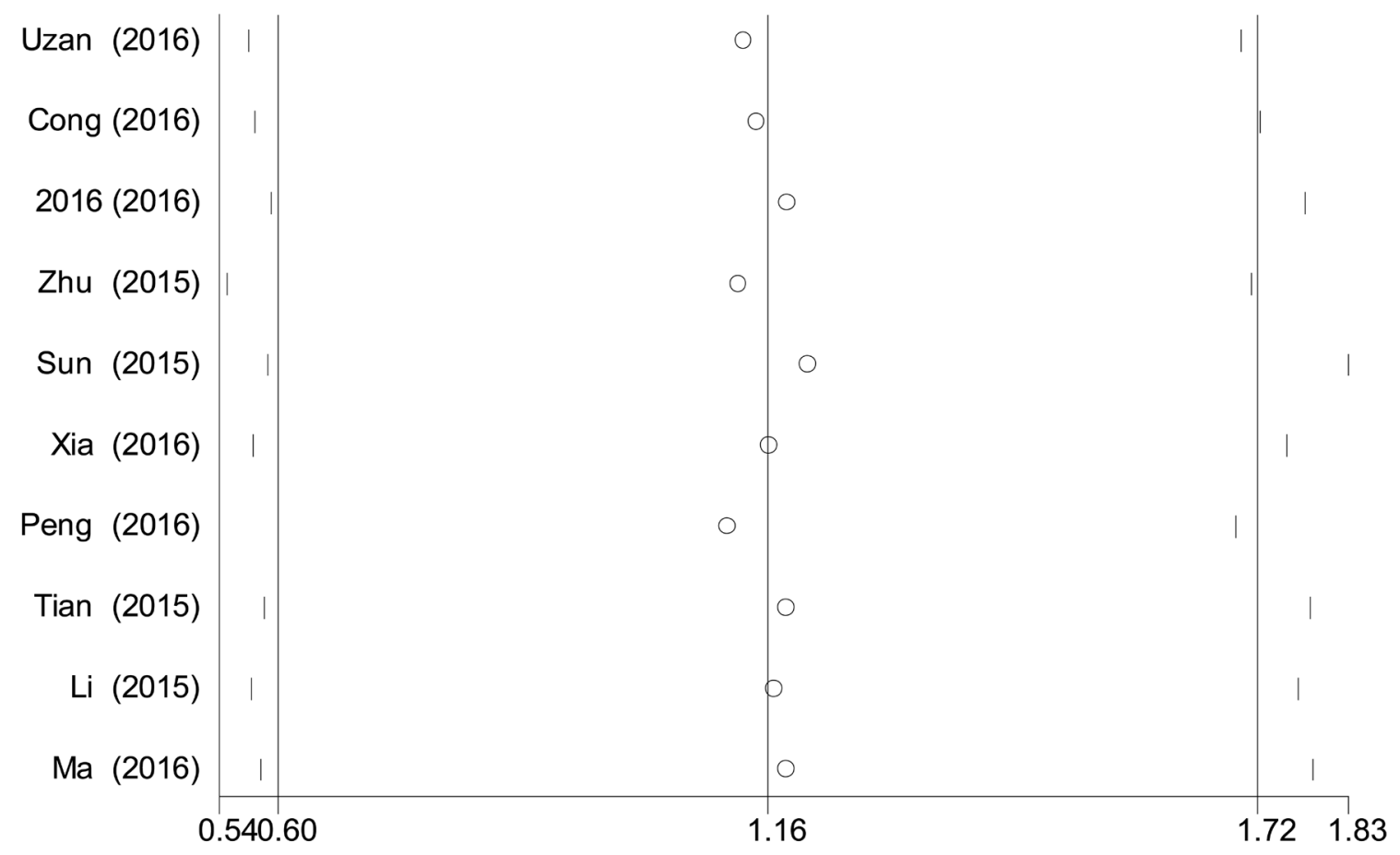

B

Meta-analysis estimates, given named study is omitted

| Lower Cl Limit | Estimate Upper Cl Limit

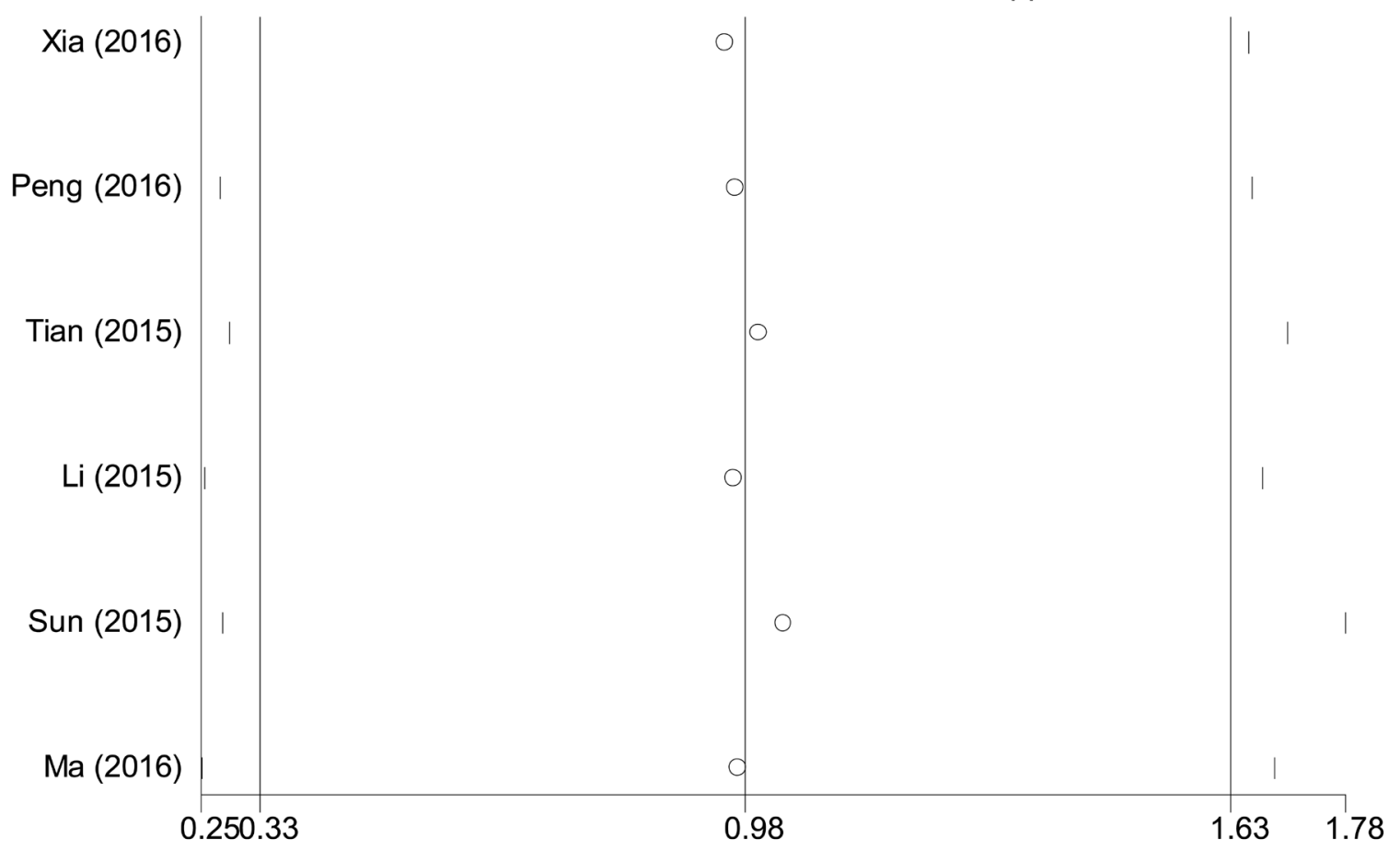

Figure 3: Influence analysis of the pooled studies. A. univariate analysis of the pooled HRs for OS time; B. multivariate analysis of the pooled HRs for OS time. 
A

Begg's funnel plot with pseudo $95 \%$ confidence limits

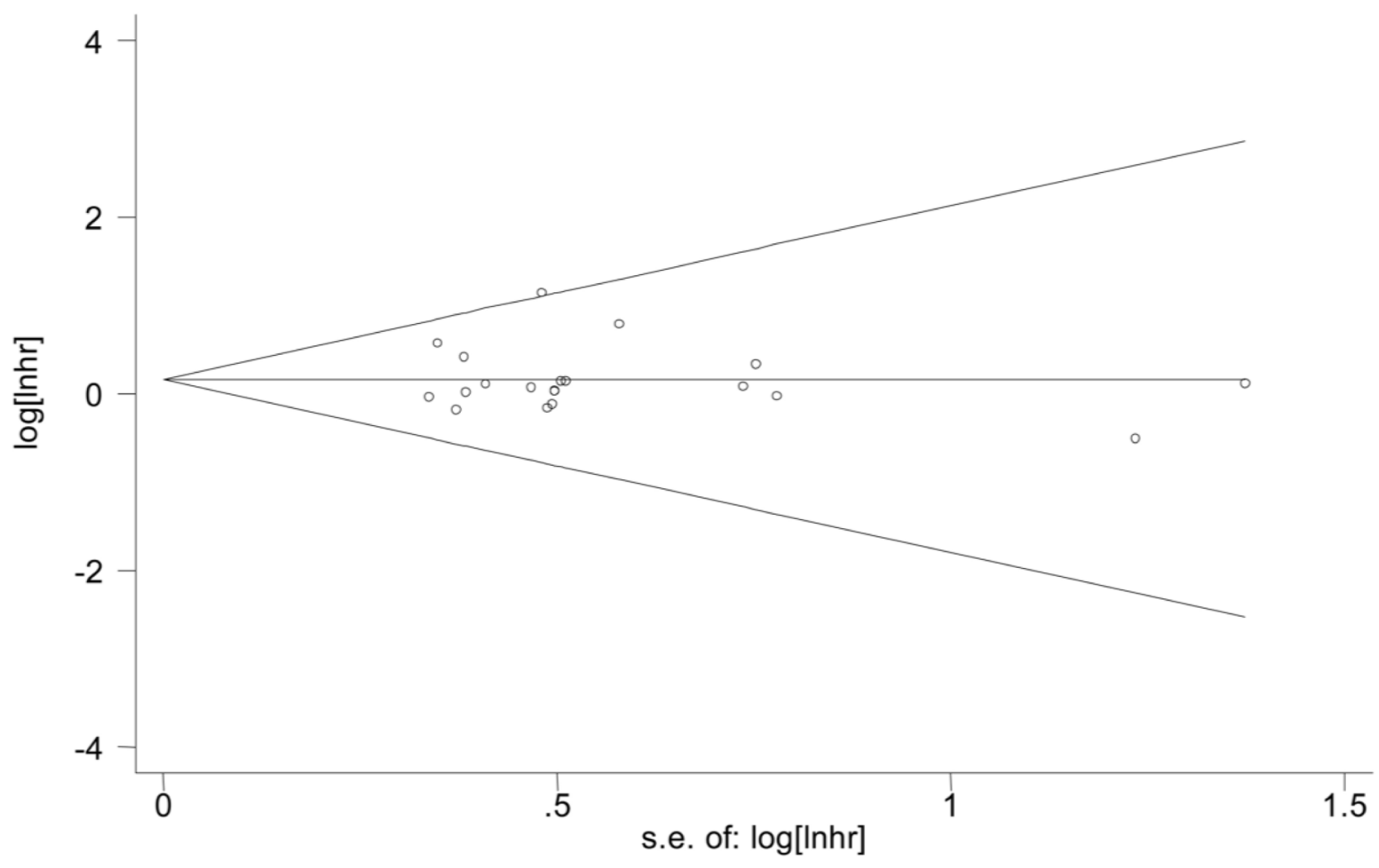

B

\section{Egger's publication bias plot}

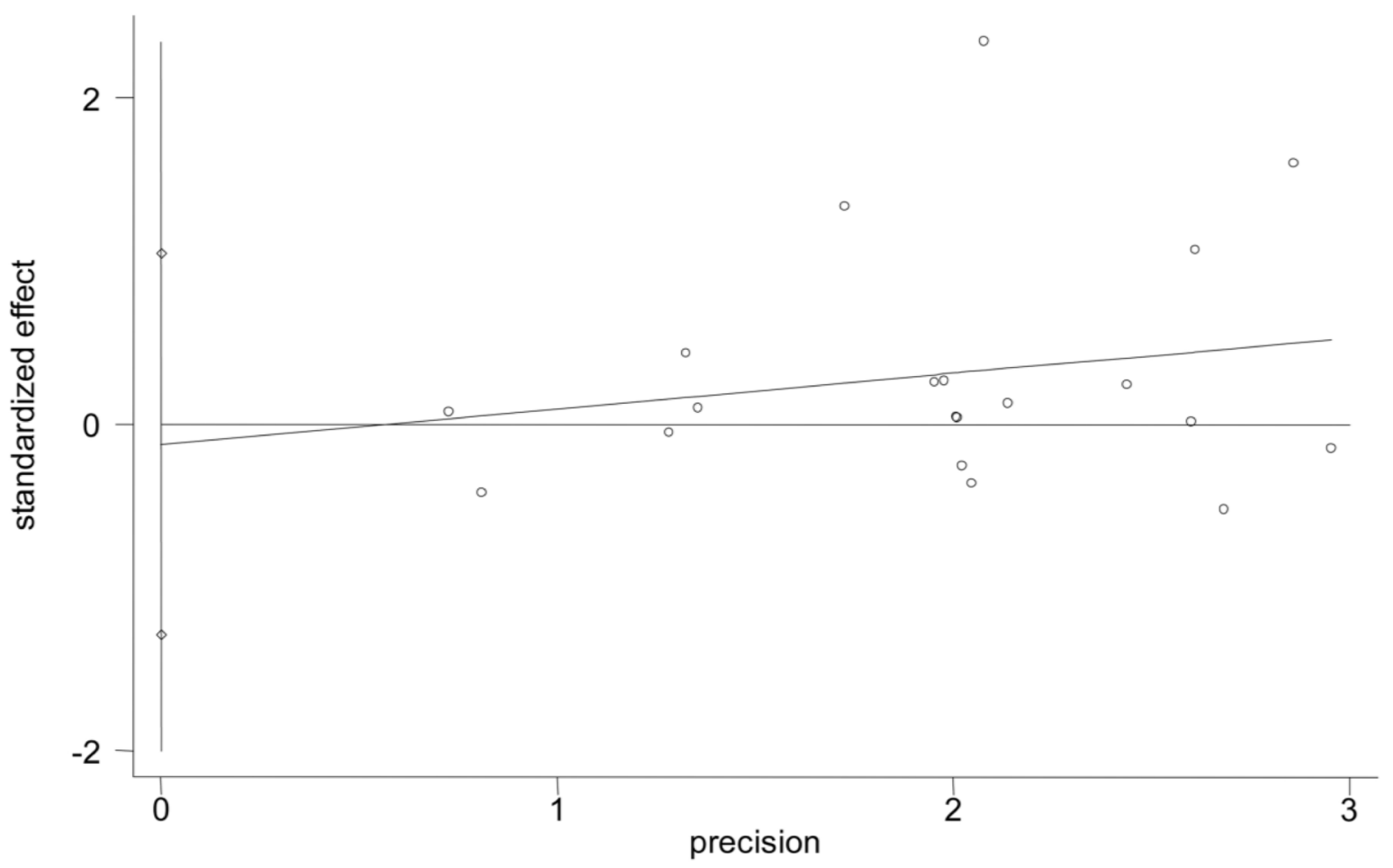

Figure 4: Publication bias of the overall pooled analyses evaluated by Bgger's funnel plot and Egger's publication bias plot. A. Bgger's funnel plot $(P=0.442)$; B. Egger's publication bias plot $(P=0.142)$. 
of osteosarcoma. Similar results were obtained in merged PFS and EFS of the osteosarcoma patients as well. A newly published meta-analysis study from Chen et al evidenced that lncRNAs could act as promising markers for prognosis as well as lymph node metastasis and distant metastasis in renal cell carcinoma [11]. Another pooled analysis conducted by Hong et al also manifested that lncRNA-UCA1 expression status is markedly correlated with poor OS and PFS times in various cancers [25]. Agree with the above findings, our data strengthened the observation that lncRNA profiles sustain a pivotal role in forecasting prognosis in osteosarcoma.

LncRNAs are involved in the carcinogenesis as well as progress and metastasis of osteosarcoma $[14,16$, $17,19,20,22]$. In our subgroup analysis stratified by clinicopathological features, we found that tumor size, clinical stage and distant metastasis were negatively associated with OS time of the osteosarcoma patients. More importantly, lncRNA profiling was found to be strongly correlated with tumor size, clinical stage and distant metastasis. The results allowed us to suggest that lncRNA(s) expression is correlated to osteosarcoma with a more aggressive behavior. A study meta-analyzed the associations between lncRNA-MALAT1 expression and clinicopatholoical characteristics corroborates our findings: MALAT1 level was demonstrated to be closely associated with clinical stage and lymph node metastasis in renal cell carcinoma [11]. Another investigation from Jing et al presented the similar results [26]. Nevertheless, some research found no significant associations between lncRNA-HULC expression and clinicopathology features in osteosarcoma [21]. Thus, more evidences are still warranted to reinforce our findings.

Among the altered lncRNA profiles, 7 lncRNAs involved TUG1, 91H, HULC, BANCR, FGFR3-AS1, HOTTIP and OMRUL [14, 16-19, 21-23], were notably increased in patients with osteosarcoma and strongly correlated to worse clinical outcomes, indicating that such lncRNAs may play oncogenic roles in maintaining tumor progression. Intriguingly, Zhang's investigation had evidenced that some of the above lncRNAs, such as TUG1, was down-regulated in non-small cell lung carcinoma and also indicated poor survival in such disease [27]. On the other hand, abundance of two types of IncRNAs, MEG3 and TUSC7 were demonstrated to be down-regulated in osteosarcoma patients and significantly associated with survival times [13, 20]. It has been reported that expression of MEG3 RNA was detectable in many normal tissues, but lost or decreased in many primary cancers [28]. Similarly, expression level of TUSC7 was lower in osteosarcoma tissues than nontumor tissues, and that silencing of TUSC7 expression in osteosarcoma cells resulted in promoted cell viability [13]. These findings indicate that expression of lncRNAs may be tissue-specific and act distinct but different roles in cancer biology.
Despite the promising data, the current study still yields some limitations. Firstly, a total of 9 individual lncRNAs were included and the pooled results, to some extent, only provide an overview of the prognostic utilities of all current studied lncRNAs, yet suitable lncRNA(s) or expression patterns or other novel lncRNAs for clinical applications should be further identified and confirmed. Secondly, the enrolled studies encountered restricted patient sizes, which, to some extent, may compromise the overall accuracy of the pooled results. Thirdly, most of studies were conducted in Chinese and the results may be more applicable to this racial population group. Last, many factors included different cut-off points for lncRNA signatures may eventually increase the heterogeneity among studies; additionally, different clinical stages, treatments (surgical remission), chemotherapy responses, as well as unclear concomitant disease conditions among patients, may eventually affect the endpoints of survival in osteosarcoma.

Taken together, the current study demonstrated that lncRNA signatures hallmark promising value in surveillance of clinical outcomes, and therefore could be developed as predictive biomarkers for osteosarcoma survival. Notwithstanding, other large-scale and high quality investigations are still warranted to further validate the clinical utilities of lncRNAs (single or in parallel) for osteosarcoma.

\section{MATERIALS AND METHODS}

\section{Publication search}

The entire contents of this study are in compliance with the guidelines of Preferred Reporting Items for Systematic Reviews and Meta-analysis (PRISMA) [29]. We conducted a computerized literature search in the online PubMed, EMBASE, CNKI, and WANFANG databases from inception to July $31^{\text {st }} 2016$. The search keywords were predefined as "long non coding RNA" or "IncRNA", "osteosarcoma" or "osteogenic sarcoma", and "prognosis" or "hazard ratio" or "HR", etc. To avoid missing eligible studies, we manually searched the article references for data collection as well.

\section{Eligibility criteria}

The inclusion criteria were: (a) cohort design; (b) studies addressed the association between lncRNA(s) expression and prognosis of osteosarcoma; (c) the primary endpoints as OS, PFS, DFS (disease-free survival) or EFS were clearly defined; and (d) the HRs with corresponding $95 \%$ CIs were available or can be calculated indirectly. The exclusion criteria were: (a) studies unrelated to the prognostic utility of $\operatorname{lncRNA}(\mathrm{s})$ in osteosarcoma; (b) data 
was unclearly presented and insufficient to perform the statistical analysis, and (c) basic research, animal studies, reviews, letters and comments, etc.

\section{Data extraction and quality assessment}

Two authors (S. Wang and T. Li) independently extracted the data with the contents of name of the first author, country, publication date, study design, ethnicity, patient size, sample type, lncRNA profile, test method, survival endpoints (OS, PFS, DFS or EFS), follow-up months, HRs and 95\%CIs, and $P$ values, etc. Differences in opinion from the reviewers were finally resolved by group consensus.

Study quality of all cohort studies was judged utilizing the Newcastle-Ottawa Scale (NOS) checklists, wherein, cohort selection, comparability and outcome ascertainment of each study were estimated, with a maximum evaluation score of 9 (a score $\geq 6$ was rated as study with high quality)[24]. If the enrolled single study received a relatively low evaluation score after quality assessment, it will be excluded for the final statistical analysis.

\section{Statistical analysis}

All statistical analyses were undertaken via Stata 12.0 program (Stata Corporation, College Station, TX, USA). Degrees of study heterogeneity was examined by Chi-squared and I-squared tests, and significant level was set at $P<0.05$ (I-squared $>50 \%$ ) [30]. The DerSimonian and Laird method (random-effect model) will be applied in case of significant heterogeneity existed among studies, otherwise, the Mantel-Haenszel method (fixed-effect model) will be chosen for the analysis [31]. For the pooled analysis, HRs and the corresponding 95\% CIs were extracted and meta-analyzed for aggregation of the survival results. In the stratified analysis, the $P$ values were merged by utilizing Fisher's test. Publication bias was checked by Egger's and Bgger's tests, and $P<0.05$ was deemed as statistical significant [32].

\section{CONFLICTS OF INTEREST}

All authors declare that there are no conflicts of interest.

\section{REFERENCES}

1. Mirabello L, Troisi RJ, Savage SA. Osteosarcoma incidence and survival rates from 1973 to 2004: data from the Surveillance, Epidemiology, and End Results Program. Cancer. 2009; 115:1531-1543.

2. Bielack SS, Kempf-Bielack B, Delling G, Exner GU,
Flege S, Helmke K, Kotz R, Salzer-Kuntschik M, Werner M, Winkelmann W, Zoubek A, Jurgens H, Winkler K. Prognostic factors in high-grade osteosarcoma of the extremities or trunk: an analysis of 1,702 patients treated on neoadjuvant cooperative osteosarcoma study group protocols. J Clin Oncol. 2002; 20:776-790.

3. Bielack SS, Carrle D, Hardes J, Schuck A, Paulussen M. Bone tumors in adolescents and young adults. Curr Treat Options Oncol. 2008; 9:67-80.

4. Brosnan CA, Voinnet O. The long and the short of noncoding RNAs. Curr Opin Cell Biol. 2009; 21:416-425.

5. Fang Y, Fullwood MJ. Roles, Functions, and Mechanisms of Long Non-coding RNAs in cancer. Genomics Proteomics Bioinformatics. 2016; 14:42-54.

6. Dhamija S, Diederichs S. From junk to master regulators of invasion: lncRNA functions in migration, EMT and metastasis. Int J Cancer. 2016; 139:269-280.

7. Chen LL. Linking Long Noncoding RNA Localization and Function. Trends Biochem Sci. 2016; 41:761-772.

8. Zhang S, Chen S, Yang G, Gu F, Li M, Zhong B, Hu J, Hoffman A, Chen M. Long noncoding RNA HOTAIR as an independent prognostic marker in cancer: a meta-analysis. PloS one. 2014; 9:e105538.

9. Tian $\mathrm{X}, \mathrm{Xu}$ G. Clinical value of lncRNA MALAT1 as a prognostic marker in human cancer: systematic review and meta-analysis. BMJ Open. 2015; 5:e008653.

10. Serghiou S, Kyriakopoulou A, Ioannidis JP. Long noncoding RNAs as novel predictors of survival in human cancer: a systematic review and meta-analysis. Mol Cancer. 2016; 15:50.

11. Chen J, Chen Y, Gu L, Li X, Gao Y, Lyu X, Chen L, Luo G, Wang L, Xie Y, Duan J, Peng C, Ma X. LncRNAs act as prognostic and diagnostic biomarkers in renal cell carcinoma: a systematic review and meta-analysis. Oncotarget. 2016; 7:74325-74336. doi: 10.18632/ oncotarget.11101.

12. Chen F, Mo J, Zhang L. Long noncoding RNA BCAR4 promotes osteosarcoma progression through activating GLI2-dependent gene transcription. Tumour Biol. 2016. 37:13403-13412.

13. Cong M, Li J, Jing R, Li Z. Long non-coding RNA tumor suppressor candidate 7 functions as a tumor suppressor and inhibits proliferation in osteosarcoma. Tumour Biol. 2016; 37:9441-9450

14. Li F, Cao L, Hang D, Wang F, Wang Q. Long non-coding RNA HOTTIP is up-regulated and associated with poor prognosis in patients with osteosarcoma. Int J Clin Exp Pathol. 2015; 8:11414-11420.

15. Li W, He X, Xue R, Zhang Y, Zhang X, Lu J, Zhang Z, Xue L. Combined over-expression of the hypoxia-inducible factor 2alpha gene and its long non-coding RNA predicts unfavorable prognosis of patients with osteosarcoma. Pathol Res Pract. 2016; 212:861-866.

16. Ma B, Li M, Zhang L, Huang M, Lei JB, Fu GH, Liu 
CX, Lai QW, Chen QQ, Wang YL. Upregulation of long non-coding RNA TUG1 correlates with poor prognosis and disease status in osteosarcoma. Tumour Biol. 2016; 37:4445-4455.

17. Peng ZQ, Lu RB, Xiao DM, Xiao ZM. Increased expression of the lncRNA BANCR and its prognostic significance in human osteosarcoma. Genet Mol Res. 2016; 15. doi: 10.4238/gmr.15017480.

18. Sun J, Wang X, Fu C, Wang X, Zou J, Hua H, Bi Z. Long noncoding RNA FGFR3-AS1 promotes osteosarcoma growth through regulating its natural antisense transcript FGFR3. Mol Biol Rep. 2016; 43:427-436.

19. Sun XH, Yang LB, Geng XL, Wang R, Zhang ZC. Increased expression of IncRNA HULC indicates a poor prognosis and promotes cell metastasis in osteosarcoma. Int J Clin Exp Pathol. 2015; 8:2994-3000.

20. Tian ZZ, Guo XJ, Zhao YM, Fang Y. Decreased expression of long non-coding RNA MEG3 acts as a potential predictor biomarker in progression and poor prognosis of osteosarcoma. Int J Clin Exp Pathol. 2015; 8:15138-15142.

21. Uzan VR, Lengert A, Boldrini E, Penna V, ScapulatempoNeto C, Scrideli CA, Filho AP, Cavalcante CE, de Oliveira CZ, Lopes LF, Vidal DO. High Expression of HULC Is Associated with Poor Prognosis in Osteosarcoma Patients. PLoS One. 2016; 11:e0156774.

22. Xia WK, Lin QF, Shen D, Liu ZL, Su J, Mao WD. Clinical implication of long noncoding RNA 91H expression profile in osteosarcoma patients. Onco Targets Ther. 2016; 9:46454652.

23. Zhu KP, Zhang CL, Shen GQ, Zhu ZS. Long noncoding RNA expression profiles of the doxorubicin-resistant human osteosarcoma cell line MG63/DXR and its parental cell line MG63 as ascertained by microarray analysis. Int J Clin Exp Pathol. 2015; 8:8754-8773.

24. Stang A. Critical evaluation of the Newcastle-Ottawa scale for the assessment of the quality of nonrandomized studies in meta-analyses. European journal of epidemiology. 2010; 25:603-605.
25. Hong HH, Hou LK, Pan X, Wu CY, Huang H, Li B, Nie W. Long non-coding RNA UCA1 is a predictive biomarker of cancer. Oncotarget. 2016;7:44442-44447. doi: 10.18632/ oncotarget.10142.

26. Jing $\mathrm{W}, \mathrm{Zhu} \mathrm{M}$. The significance of long noncoding RNA H19 in predicting progression and metastasis of cancers: A meta-analysis. Biomed Res Int. 2016; 2016:5902678.

27. Zhang EB, Yin DD, Sun M, Kong R, Liu XH, You LH, Han L, Xia R, Wang KM, Yang JS, De W, Shu YQ, Wang ZX. P53-regulated long non-coding RNA TUG1 affects cell proliferation in human non-small cell lung cancer, partly through epigenetically regulating HOXB7 expression. Cell Death Dis. 2014; 5:e1243.

28. Zhang X, Rice K, Wang Y, Chen W, Zhong Y, Nakayama Y, Zhou Y, Klibanski A. Maternally expressed gene 3 (MEG3) noncoding ribonucleic acid: isoform structure, expression, and functions. Endocrinology. 2010; 151:939947.

29. Moher D, Liberati A, Tetzlaff J, Altman DG. Preferred reporting items for systematic reviews and meta-analyses: the PRISMA statement. J Clin Epidemiol. 2009; 62:10061012.

30. Stenman M, Holzmann MJ, Sartipy U. Association between preoperative depression and long-term survival following coronary artery bypass surgery - A systematic review and meta-analysis. Int J Cardiol. 2016; 222:462-466.

31. Luo Y, Zhang X, Tan Z, Wu P, Xiang X, Dang Y, Chen G. Astrocyte Elevated Gene-1 as a novel clinicopathological and prognostic biomarker for gastrointestinal cancers: A meta-analysis with 2999 patients. PloS one. 2015; 10:e0145659.

32. Zhao S, Wu D, Wu P, Wang Z, Huang J. Serum IL-10 predicts worse outcome in cancer patients: A meta-analysis. PloS one. 2015; 10:e0139598. 